Supporting Information

\title{
Interstitial Site Engineering for Creating Unusual Red Emission in
} $\mathrm{La}_{3} \mathrm{Si}_{6} \mathrm{~N}_{11}: \mathrm{Ce}^{3+}$

Shihai You, ${ }^{\dagger}$ Shuxing Li, ${ }^{\dagger}$ Yongchao Jia, ${ }^{*}, \neq$ Rong-Jun Xie ${ }^{*},+$

${ }^{\dagger}$ College of Materials, Xiamen University, Xiamen, Fujian 361005, China

\#Institute of Condensed Matter and Nanosciences, Université catholique de Louvain, Chemin des étoiles 8, bte L07.03.01, B-1348 Louvain-la-Neuve, Belgium

E-mails: yongchao.jia@uclouvain.be (Y.J.); rjxie@xmu.edu.cn (R.-J.X.) 


\section{S1. Computational details}

Table S1. The Monkhorst-Pack sampling, supercell size (number of atoms), and $\mathrm{Ce}^{3+}$ doping concentration of the eleven $\mathrm{Ce}^{3+}$ doped materials.

\begin{tabular}{|c|c|c|c|}
\hline Compounds & $k$-point grid & Supercell size & $\begin{array}{c}\mathrm{Ce}^{3+} \text { concentration } \\
(\%)\end{array}$ \\
\hline $\mathrm{La}_{3} \mathrm{AlSi}_{5} \mathrm{ON}_{10}: \mathrm{Ce}_{2 \mathrm{a}, \mathrm{O}}$ & $2 \times 2 \times 2$ & 80 & 8.33 \\
\hline $\mathrm{La}_{3} \mathrm{AlSi}_{5} \mathrm{ON}_{10}: \mathrm{Ce}_{4 \mathrm{c}, \mathrm{O}}$ & $2 \times 2 \times 2$ & 80 & 8.33 \\
\hline $\mathrm{La}_{3} \mathrm{Si}_{6} \mathrm{~N}_{11}: \mathrm{Al}^{3+}, \mathrm{Ce}_{2 \mathrm{a}, \mathrm{VN} 1}$ & $1 \times 1 \times 1$ & 119 & 5.56 \\
\hline $\mathrm{La}_{3} \mathrm{Si}_{6} \mathrm{~N}_{11}: \mathrm{Al}{ }^{3+}, \mathrm{Ce}_{2 \mathrm{a}, \mathrm{VN} 2}$ & $1 \times 1 \times 1$ & 119 & 5.56 \\
\hline $\mathrm{La}_{3} \mathrm{Si}_{6} \mathrm{~N}_{11}: \mathrm{Al}^{3+}, \mathrm{Ce}_{4 c}, \mathrm{VN} 1$ & $1 \times 1 \times 1$ & 119 & 5.56 \\
\hline $\mathrm{La}_{3} \mathrm{Si}_{6} \mathrm{~N}_{11}: \mathrm{Al}^{3+}, \mathrm{Ce}_{4 \mathrm{c}, \mathrm{VN} 2 \mathrm{a}}$ & $1 \times 1 \times 1$ & 119 & 5.56 \\
\hline $\mathrm{La}_{3} \mathrm{Si}_{6} \mathrm{~N}_{11}: \mathrm{Al}^{3+}, \mathrm{Ce}_{4 \mathrm{c}, \mathrm{VN} 2 \mathrm{~b}}$ & $1 \times 1 \times 1$ & 119 & 5.56 \\
\hline $\mathrm{La}_{3} \mathrm{Si}_{6} \mathrm{~N}_{11}: \mathrm{Al}^{3+}, \mathrm{Ce}_{4 \mathrm{c}, \mathrm{VN} 3}$ & $1 \times 1 \times 1$ & 119 & 5.56 \\
\hline $\mathrm{La}_{3} \mathrm{Si}_{6} \mathrm{~N}_{11}: \mathrm{Al}^{3+}, \mathrm{Ce}_{4 \mathrm{c}, \mathrm{VN} 4}$ & $1 \times 1 \times 1$ & 119 & 5.56 \\
\hline $\mathrm{La}_{3} \mathrm{Si}_{6} \mathrm{~N}_{11}: \mathrm{Al}^{3+}, \mathrm{Ce}_{\mathrm{i}}$ & $1 \times 1 \times 1$ & 121 & 5.26 \\
\hline $\mathrm{La}_{3} \mathrm{Si}_{6} \mathrm{~N}_{11}: \mathrm{Al}^{3+}, \mathrm{Ce}_{\mathrm{ii}}$ & $1 \times 1 \times 1$ & 121 & 5.26 \\
\hline
\end{tabular}

Due to the coupling of electronic transition with lattice vibrations, the photoluminescence of lunminescent center in solids naturally appears as vibronic spectra, which are composed by the zerophonon line and phonon sidebands, and their ratio decreases with the stronger coupling strength. The coupling interaction between electronic transition and lattice vibrations is a very complex process. The nature of this physical process is the distribution of additional potential (from electronic transition) over the normal modes in the solids. Under adiabatic approximation, the Schrödinger equation of system can be solved by separation of coordinates of electron and nuclear. The eigenvalue of electron acts as the role of potential term of nucleus's equation. After an optical transition of electrons, the nucleus is out of equilibrium position following the idea of Franck-Condon principle. The additional potential is obtained due to the change of bond nature, which is from the difference localization character of electronic orbit. To reach the equilibrium position again, this additional potential needs to lose, via emitting phonons. The additional potential is usual called as Franck-Condon shift.

Following the above description, the total Franck-Condon shift is the sum of distribution term on each normal mode involved. The usual approach to solve this multidimensional problem is to use one effective phonon mode with the vibrational frequency, assumption all participated normal modes having the same frequency. Following this procedure, the multi-dimensional problem is reduced to one-dimensional one, which leads to the final well-known one-dimensional configuration coordinate diagram, as shown in 
Scheme $\mathbf{S 1}$ for the $4 \mathrm{f}-5 \mathrm{~d}$ transitions of $\mathrm{Ce}^{3+}$-doped phosphors. ${ }^{1-3}$ The transition energies and luminescence center identification are based on the calculation of $A_{g}, A_{g}{ }^{*}, A_{e}{ }^{*}$ and $A_{e}$, four coordinates in the configuration coordinated diagram. $Q_{\mathrm{g}}$ and $Q_{\mathrm{e}}$ represent the equilibrium configuration coordinates for the system with $\mathrm{Ce}^{3+}$ ion in its ground and excited states, respectively. The meanings of $A_{g}$ and $A_{g}{ }^{*}$ are the ground and excited state calculations with the ground state geometry $\left(Q_{\mathrm{g}}\right.$, in the Figure $\left.S 1\right)$, while $A_{\mathrm{e}}$ and $A_{e}{ }^{*}$ stand for the ground and excited state calculation with the excited state geometry $\left(Q_{e}\right.$, in the Figure $\mathrm{S} 1)$. The excited state geometry $\left(Q_{\mathrm{e}}\right)$ is obtained from the constrained density functional theory, which relaxed the atomic positions in the fixed cell of $Q_{\mathrm{g}}$. In the one-dimensional configuration coordinate diagram (used in the present work), other points in the potential curve can be obtained from the linear combination of ground and excited state geometry. When a photon is absorbed by the $\mathrm{Ce}-4 \mathrm{f}$ electron, the $\mathrm{Ce}^{3+}$ ion will be excited from its ground state to the excited state, corresponding to $A_{g} \rightarrow A_{g}{ }^{*}$. After the absorption, the system will be out of equilibrium due to the change in the electronic configuration of the $\mathrm{Ce}^{3+}$ ion. The atomic positions are then relaxed following the forces in the electronic excited state, which is represented by the process $A_{\mathrm{g}}{ }^{*} \rightarrow A_{\mathrm{e}}{ }^{*}$. After this lattice relaxation, the system reaches a new metastable state, at which the emission process $A_{\mathrm{e}}{ }^{*} \rightarrow A_{\mathrm{e}}$ occurs. The cycle is completed by the lattice relaxation $A_{\mathrm{e}} \rightarrow A_{\mathrm{g}}$ in the electronic ground state. Based on this idea, the absorption or emission energy of $\mathrm{LSN}: \mathrm{Al}^{3+}, \mathrm{Ce}^{3+}$ phosphor can be determined semiclassically as follows. The absorption process, with energy

$$
\Delta E_{\mathrm{abs}}=E_{\mathrm{g}}{ }^{*}-E_{\mathrm{g}}
$$

while the emission process, with energy

$$
\Delta E_{\mathrm{em}}=E_{\mathrm{e}}^{*}-E_{\mathrm{e}}
$$

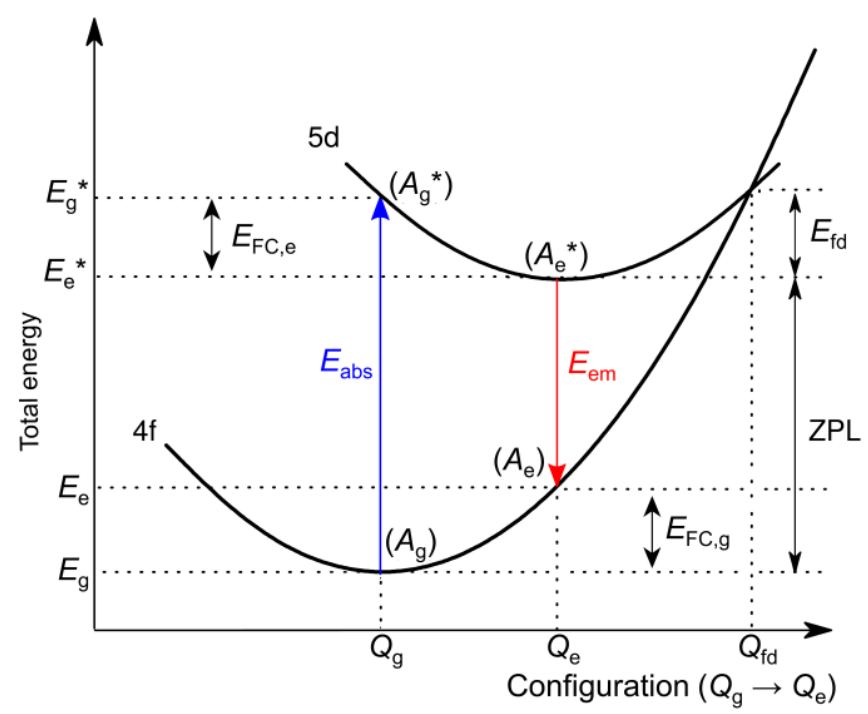

Scheme S1. One-dimensional configurational coordinate diagram for $\mathrm{LSN}: \mathrm{Al}^{3+}, \mathrm{Ce}^{3+}$ phosphor.

For the analysis of $\mathrm{Ce}^{3+}$ photoluminescence, constrained density functional theory (CDFT) was adopted for the description of excited state, following our previous works. ${ }^{1,2}$ As its name states, CDFT belongs to the framework of DFT, solving the Schrödinger equation of studied system with fixed electron occupancy. It suffers from the drawbacks of the conventional DFT, such as band gap problem, but can 
successfully create the electron-hole interaction during the neutral excitation and provide valuable information about the system in the excited state.

Here, it is worthy to note that the CDFT method provides a systematical error on the transition energies. In our previous work, a statistical analysis has been performed on the first-principles results. ${ }^{2}$ For the absorption and emission energies, a linear correlation between fistt-principles and experimental results has been found:

$$
\begin{aligned}
& E_{\text {abs-correct }}=\left(E_{\mathrm{abs}}-0.142\right) / 1.01 \\
& E_{\mathrm{em}-\text { correct }}=\left(E_{\mathrm{em}}+0.066\right) / 1.08
\end{aligned}
$$

where $E_{\mathrm{abs}}$ and $E_{\mathrm{em}}$ are transition energies $(\mathrm{eV})$ calculated by the first-principles calculation.

The thermal quenching of $\mathrm{LSN}: \mathrm{Al}^{3+}, \mathrm{Ce}^{3+}\left(\mathrm{Ce}_{2 a}\right.$ and $\mathrm{Ce}_{i i}$ luminescent center, respectively) was analyzed by the auto-ionization model, sketched in Scheme S2. ${ }^{3,4}$ This model relies on the possibility for the electron in the excited state to be driven into the conduction band, e.g. by thermal lattice vibrations, resulting in its delocalization, after which the radiative recombination rate drops considerably, and other nonradiative recombination mechanisms have the time to occur. The electron delocalization usually results in a geometry relaxation in which the local collective displacement of atoms from $Q_{\mathrm{e}}$ to $Q_{\mathrm{dc}}$ might be quite different from the one observed when going from $Q_{g}$ to $Q_{\mathrm{e}}$. The total energy of both the Ce-5d and the delocalized electron states changes with the collective displacement of atoms from $Q_{\mathrm{e}}$ to $Q_{\mathrm{dc}}$. It reaches its minimum at $Q_{\mathrm{e}}$ when the electron occupies the Ce-5d state, and at $Q_{\mathrm{dc}}$ when the electron is delocalized. Consequently, we distinguish the configuration coordinate between $Q_{\mathrm{e}} \rightarrow Q_{\mathrm{dc}}$ from the one of $Q_{\mathrm{g}} \rightarrow Q_{\mathrm{e}}$. Also, the CBM zone, in grey in Scheme $\mathbf{S 2}$, is delimited by a parabola in configuration coordinate diagrams because they represent total energies and not electronic energies, and one can thus distinguish an optical (fixed geometry, $Q_{\mathrm{e}}$ ) and a thermal (relaxed geometry, $Q_{\mathrm{e}} \rightarrow Q_{\mathrm{dC}}$ ) energy difference between the total energy of the Ce-5d electron situation and the total energy of the delocalized CBM electron situation. 


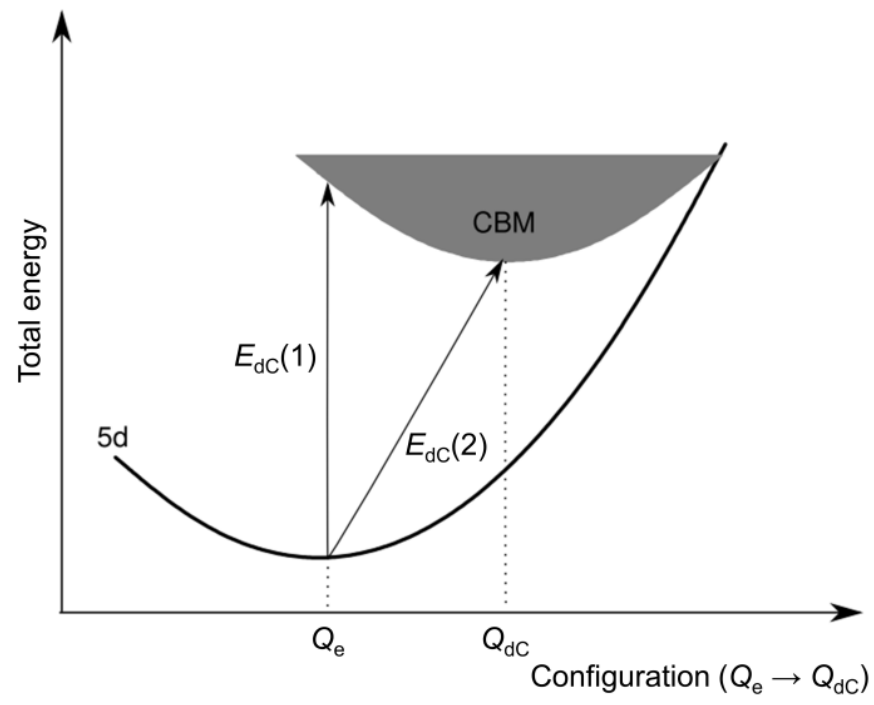

Scheme S2. Configuration coordinate diagram for the auto-ionization model. $E_{d c}(1)$ is the (optical) energy difference corresponding to transition from the Ce-5d excited state at its minimum energy geometry $\left(Q_{e}\right)$ to the delocalized state without geometry relaxation, while $E_{\mathrm{dc}}(2)$ is the (thermal) energy difference in which the final state includes geometry relaxation to its minimum energy geometry $\left(Q_{\mathrm{dc}}\right)$.

However, from the theoretical viewpoint, the calculation of the absolute energy barrier for the thermal quenching via auto-ionization model, $E_{\mathrm{dc}}$, is not an easy task. Because it depends on the band gap, its accurate estimation would need to go beyond DFT-PBE, which is subject to the well-known DFT band gap problem, e.g. using hybrid functionals or the GW approximation. Also, the effect of geometry relaxation (from $Q_{\mathrm{e}}$ to $Q_{\mathrm{dc}}$ ) on the absolute energy barrier of thermal quenching should be taken into account. Here, we try to understand the thermal stability of different $\mathrm{Ce}^{3+}$ luminescent centers in their electronic excited state. Instead of focusing on the absolute value for the energy barrier within the auto-ionization model, we will actually compare variations of $E_{\mathrm{dc}}$ between the different luminescent centers, based on the optical (fixed geometry) and thermal (relaxed geometry) transition energy of $\varepsilon\left(\mathrm{Ce}^{3+,} / \mathrm{Ce}^{4+}\right)$, indeed taking geometry relaxation effects into account. Thus we bypass the band-gap problem, but include the geometry dependence, as follows:

$E_{\mathrm{dc}}$ can be calculated from the difference between the conduction band energy, $\varepsilon(\mathrm{c})$, and the so-called transition energy level, $\varepsilon\left(\mathrm{Ce}^{3+,}, \mathrm{Ce}^{4+}\right):^{5}$

$$
E_{\mathrm{dC}}=\varepsilon(\mathrm{c})-\varepsilon\left(\mathrm{Ce}^{3+,{ }^{*}} / \mathrm{Ce}^{4+}\right)
$$

The transition energy level is the Fermi level, $\epsilon_{\mathrm{f}}$, when the formation energies of $\mathrm{Ce}^{3+,{ }^{*}}, E_{\mathrm{f}}\left(\mathrm{Ce}^{3+,{ }^{*}}\right)$, and $\mathrm{Ce}^{4+}, E_{\mathrm{f}}\left(\mathrm{Ce}^{4+}\right)$, ions are equal. They are obtained from

$$
\begin{gathered}
E_{\mathrm{f}}\left(\mathrm{Ce}^{3+,{ }^{*}}\right)=E_{\mathrm{tot}}\left(\mathrm{Ce}^{3+,{ }^{*}}\right)-E_{\mathrm{tot}}(\mathrm{bulk})+\mu_{\mathrm{La}}-\mu_{\mathrm{Ce}} \\
E_{\mathrm{f}}\left(\mathrm{Ce}^{4+}\right)=E_{\mathrm{tot}}\left(\mathrm{Ce}^{4+}\right)-E_{\mathrm{tot}}(\mathrm{bulk})+\mu_{\mathrm{La}}-\mu_{\mathrm{ce}}+\epsilon_{\mathrm{f}}+E_{\mathrm{corr}}
\end{gathered}
$$


where $E_{\text {tot }}\left(\mathrm{Ce}^{3+,{ }^{*}}\right)$ is the total energy of the (neutral) supercell with excited state $\mathrm{Ce}^{3+,{ }^{*}}$ ion, $E_{\text {tot }}\left(\mathrm{Ce}^{4+}\right)$ is the total energy of the (charged) supercell with $\mathrm{Ce}^{4+}$ ion, $E_{\text {tot }}\left(\right.$ bulk) is the total energy of the undoped LSN:Al ${ }^{3+}$ supercell, $\mu_{\mathrm{La}}$ and $\mu_{\mathrm{Ce}}$ are the chemical potentials of $\mathrm{La}$ atom and $\mathrm{Ce}$ atom, respectively. $E_{\mathrm{corr}}$ gathers the correction terms that are needed when charged systems are treated with periodic supercells, which is the case for the $\mathrm{Ce}^{4+}$ ion supercell. In the present work, we consider the charged monopole correction, which is the dominant contribution, described by a Madelung-type formula. ${ }^{6}$ The calculation details can be found in our previous work. ${ }^{7}$ Computing the transition energy level by equating Eq.(6) and Eq. (7) yields:

$$
\varepsilon\left(\mathrm{Ce}^{3+,{ }^{*}} / \mathrm{Ce}^{4+}\right)=E_{\text {tot }}\left(\mathrm{Ce}^{3+,{ }^{*}}\right)-E_{\text {tot }}\left(\mathrm{Ce}^{4+}\right)-E_{\text {corr }}
$$

For $E_{\text {tot }}\left(\mathrm{Ce}^{4+}\right)$, one can work with the geometry from the excited state $\mathrm{Ce}^{3+,{ }^{*}}$ system $\left(Q_{\mathrm{e}}\right)$ or from the relaxed geometry of the ionized state $\mathrm{Ce}^{4+}$ system $\left(Q_{\mathrm{dc}}\right)$, obtaining the optical $E_{\mathrm{dc}}(1)$ or thermal $E_{\mathrm{dc}}(2)$. Adding a delocalized electron to the latter does not change the relaxed geometry. The formulation Eq.(5) allows us to bypass the DFT band-gap problem, in that we will compare $E_{\mathrm{dc}}$ values of differennt $\mathrm{Ce}^{3+}$ luminescent centers $\left(\mathrm{Ce}_{2 \mathrm{a}}\right.$ and $\left.\mathrm{Ce}_{\mathrm{ii}}\right)$, for which the contribution $\varepsilon(\mathrm{c})$ to Eq.(5) is the same, while the remaining $\varepsilon\left(\mathrm{Ce}^{3+, *} / \mathrm{Ce}^{4+}\right)$ contribution is not affected by the energy of the conduction band with respect to the valence band, or with respect to the Fermi energy. Then, the differences of $E_{\mathrm{dc}}$ (including $E_{\mathrm{dc}}(1)$ for the optical case and $E_{\mathrm{dc}}(2)$ for the thermal case) between $\mathrm{Ce}_{2 \mathrm{a}}$ and $\mathrm{Ce}_{\mathrm{ii}}$ centers can be calculated via Eq.(5), through the computation of the transition transition energy level, $\varepsilon\left(\mathrm{Ce}^{3+,{ }^{*}} / \mathrm{Ce}^{4+}, \mathrm{Q}_{\mathrm{e}}\right)$ and $\varepsilon\left(\mathrm{Ce}^{3+,{ }^{*}} / \mathrm{Ce}^{4+}\right.$, $Q_{\mathrm{dC}}$ ), respectively. 


\section{S2. Crystal structure of $\mathrm{La}_{3} \mathrm{Si}_{6} \mathrm{~N}_{11}$}
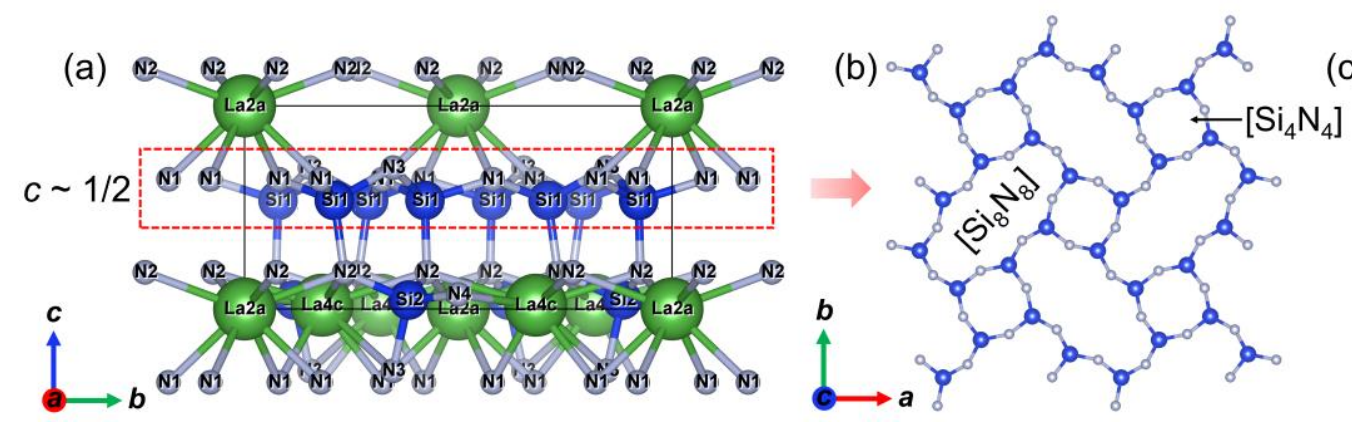

(c)

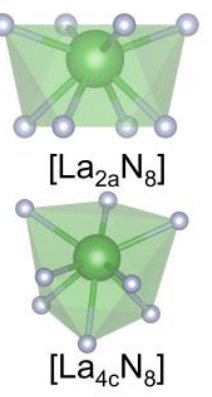

Figure S1. (a) Crystal structure of $\mathrm{La}_{3} \mathrm{Si}_{6} \mathrm{~N}_{11}$ (LSN) along [100]; (b) viewing of the $c \sim 1 / 2$ layer in projection along [001] formed with $\left[\mathrm{Si}_{4} \mathrm{~N}_{4}\right]$ and $\left[\mathrm{Si}_{8} \mathrm{~N}_{8}\right]$ rings; (c) $\left[\mathrm{La}_{2} \mathrm{~N}_{8}\right]$ and $\left[\mathrm{La}_{4} \mathrm{c} \mathrm{N}_{8}\right]$ polyhedra.

Table S2. Relaxed La-N bond lengths $(\AA)$ of the La crystallographic sites in LSN.

\begin{tabular}{ccc}
\hline Bond & GGA-PAW & Experiment $^{8}$ \\
\hline La2a-N1 $(\times 4)$ & 2.652 & 2.650 \\
La2a-N2 $(\times 4)$ & 2.659 & 2.644 \\
La2a-N (Average) & 2.656 & 2.647 \\
La4c-N1 (×2) & 2.528 & 2.551 \\
La2a-N2a (×2) & 2.674 & 2.674 \\
La2a-N2b (×2) & 2.893 & 2.853 \\
La4c-N3 & 2.823 & 2.863 \\
La4c-N4 & 2.640 & 2.623 \\
Laa4c-N (Average) & 2.707 & 2.705 \\
\hline
\end{tabular}




\section{S3. Structure and morphology}
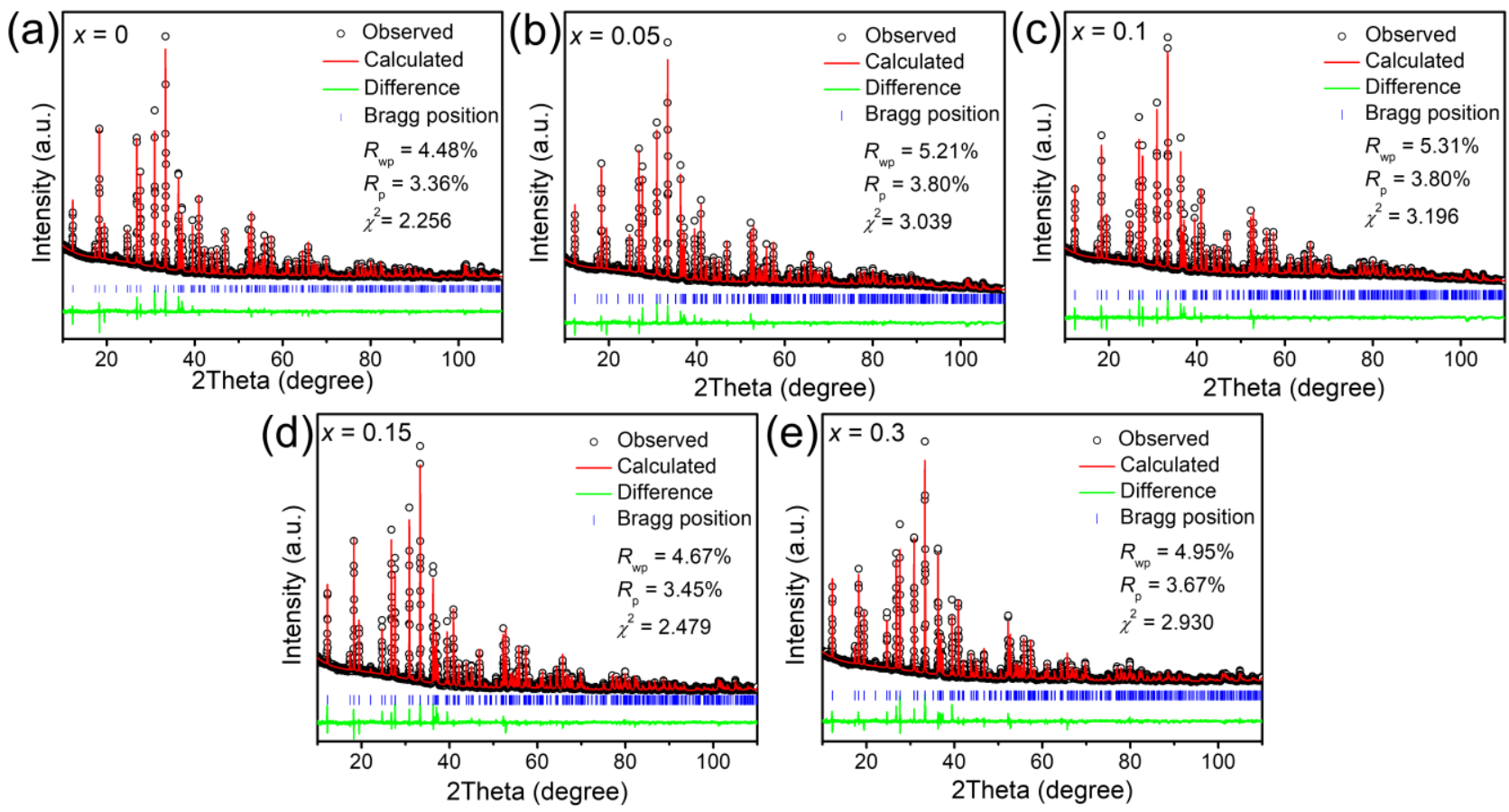

Figure S2. XRD Rietveld refinements of LSN: $x \mathrm{Al}^{3+}, \mathrm{Ce}^{3+}(x=0,0.05,0.10,0.15 .0 .30)$ samples.
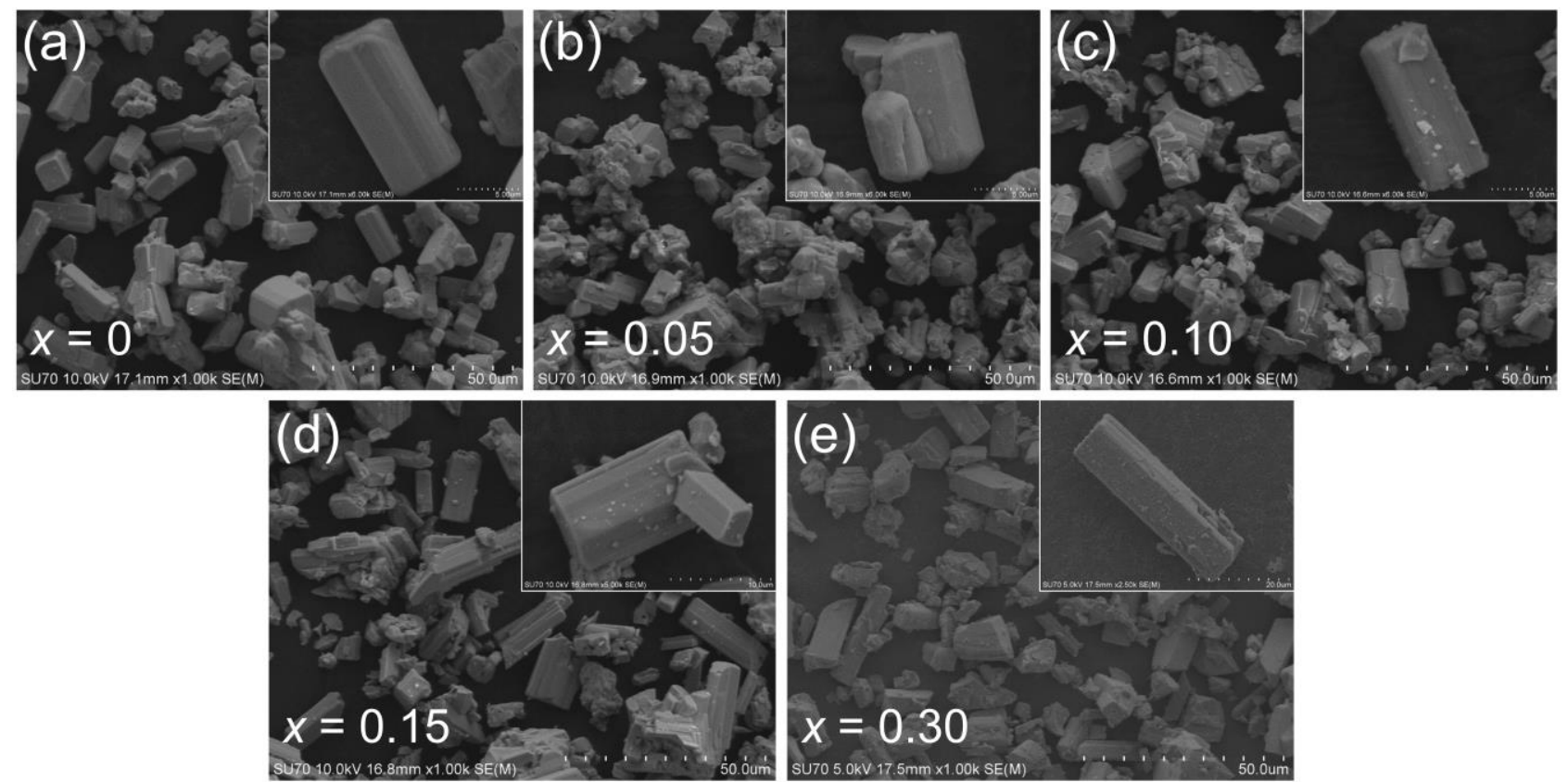

Figure S3. SEM images of $\mathrm{LSN}: x \mathrm{Al}^{3+}, \mathrm{Ce}^{3+}(x=0,0.05,0.10,0.15 .0 .30)$ samples; and the insets are corresponding enlarged single particles. 


\section{S4. Photoluminescence}

This section studied the codoping influence of $\mathrm{Al}^{3+}$ ions on the photoluminescence of LSN: $\mathrm{Al}^{3+}, \mathrm{Ce}^{3+}$. Figure S4a shows that the intensity, position and shape of emission spectra have largely changed upon $\mathrm{Al}^{3+}$ ions introduction. The emission intensity significantly decreased with increasing $\mathrm{Al}^{3+}$ concentration, while the emission spectra were largely red shifted and broadened. New excitation band at green region and new emission band at red region were formed (Figure 3a, b). Figure S4b-c presents the emission spectra of $\mathrm{LSN}: x \mathrm{Al}^{3+}, \mathrm{Ce}^{3+}(x=0.05-0.3)$ under $530 \mathrm{~nm}$ excitation, showing broad and red emission bands. To further analyze the red emission phenomenon, the emission spectra of $\mathrm{LSN}: 0.2 \mathrm{Al}^{3+}, \mathrm{Ce}^{3+}$ was well decomposed into two sub-bands peaking at 14117 and $16080 \mathrm{~cm}^{-1}(622$ and $708 \mathrm{~nm}$ ) with a typical energy difference of about $2000 \mathrm{~cm}^{-1}$ by Gaussian fitting (Figure S4d), which can be assigned to only one crystallographic site of $\mathrm{Ce}^{3+}$ in the host lattice.
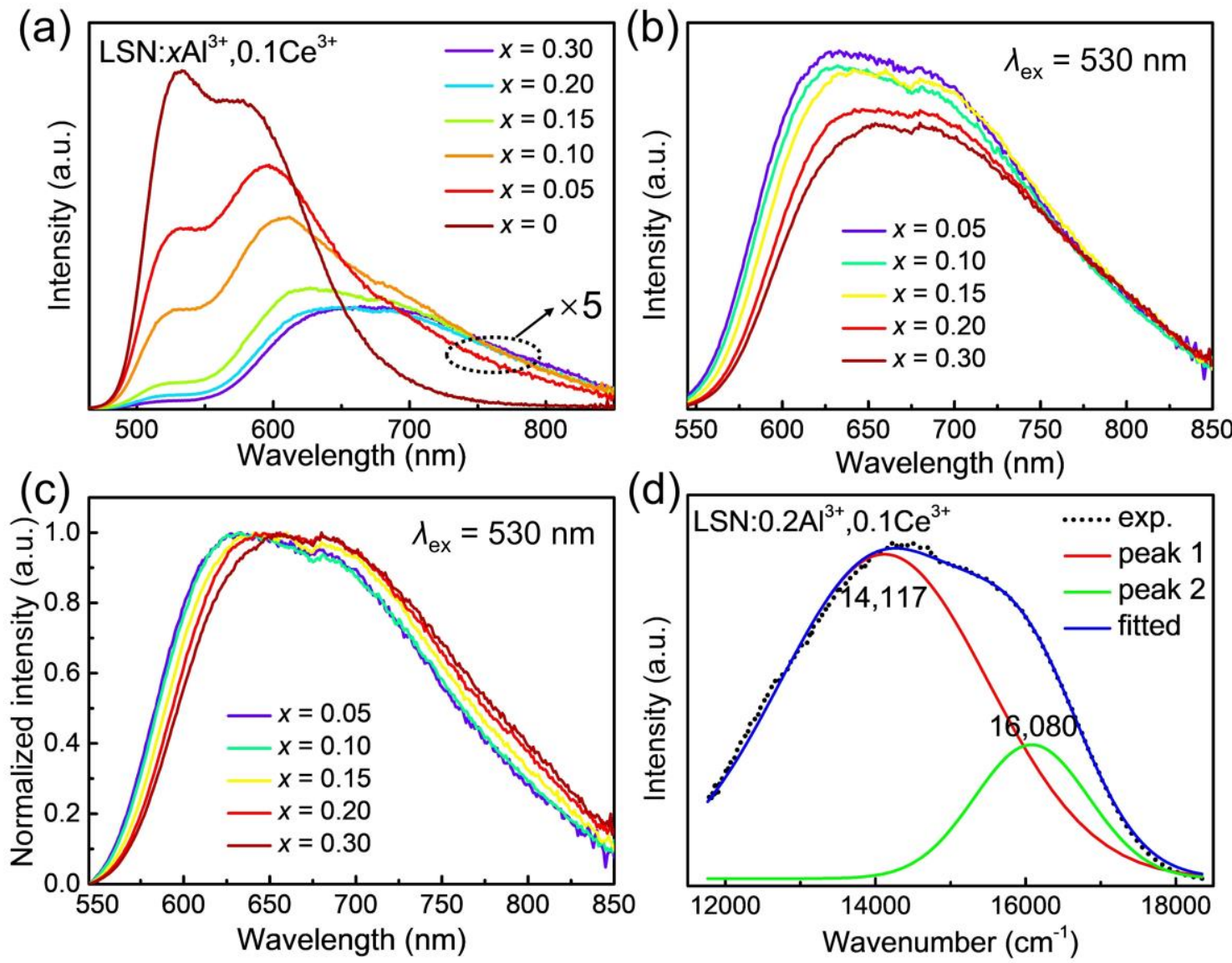

Figure S4. (a) PL spectra of LSN:xAl ${ }^{3+}, \mathrm{Ce}^{3+}(x=0-0.3)$ phosphors under $450 \mathrm{~nm}$ excitation; (b) PL spectra and (c) normalized PL spectra of LSN:xAl ${ }^{3+}, \mathrm{Ce}^{3+}(x=0.05-0.3)$ phosphors under $530 \mathrm{~nm}$ excitation; (d) Gaussian fitting of emission spectrum of $\mathrm{LSN}: 0.2 \mathrm{Al}^{3+}, \mathrm{Ce}^{3+}$ excited by $530 \mathrm{~nm}$ light.

Figure S5 shows the decay curves of LSN: $\left.x A\right|^{3+}, \mathrm{Ce}^{3+}(x=0$ and 0.2$)$ phosphors monitored at different wavelength under $445 \mathrm{~nm}$ blue LD excitation. The decay curves of $x=0$ sample monitored at 530 and 650 $\mathrm{nm}$ can be nicely fitted with the mono-exponential decay, yielding a lifetime of 34.46 and $37.63 \mathrm{~ns}$, respectively, which are in good accordance with the $\mathrm{Ce}_{2 a}$ center in LSN reported in previous references. ${ }^{9}$ 
Similarly to the significant effects on photoluminescence spectra, the Al introducing also largely changes the decay time of $\mathrm{LSN}: \mathrm{Al}^{3+}, \mathrm{Ce}^{3+}$ phosphors. The decay curves of $x=0.2$ sample observed at 530 and 700 $\mathrm{nm}$ can best be fitted with the bi-exponential decay, respectively:

$$
I=A_{1} \exp \left(-t / T_{1}\right)+A_{2} \exp \left(-t / T_{2}\right)
$$

where $I$ stands for the fluorescence intensity at time $t, A_{1}$ and $A_{2}$ are constants, and $\tau_{1}, T_{2}$ are short and long lifetimes for exponential components, respectively. The decay curve of monitored at $530 \mathrm{~nm}$ (a similar $\mathrm{Ce}_{2 \mathrm{a}}$ center) yields two separate lifetimes of $\tau_{1}=\sim 2 \mathrm{~ns}$ and $\tau_{2}=\sim 27 \mathrm{~ns}$, while that observed at $700 \mathrm{~nm}$ (newly formed $\mathrm{Ce}_{\mathrm{Al}}$ center) has two individual lifetimes of $\tau_{1}=\sim 13 \mathrm{~ns}$ and $\tau_{2}=\sim 53 \mathrm{~ns}$. The average decay time of $\mathrm{Ce}_{2 \mathrm{a}}$ and $\mathrm{Ce}_{\mathrm{Al}}$ in LSN:0.2Al ${ }^{3+}, \mathrm{Ce}^{3+}$ is calculated to be 19.88 and $43.03 \mathrm{~ns}$, respectively, according to the $\tau_{1}$ and $\tau_{2}$ values. The deviation from the mono-exponential decay and the shortened lifetime of $\mathrm{Ce}_{2 a}$ indicate there are easier non-radiative relaxation pathways formed in the energy transition process, which also limits the emission intensity and thermal stability. In general, the red-emitting $\mathrm{LSN}: \mathrm{Al}^{3+}, \mathrm{Ce}^{3+}$ phosphors still well inherit the short decay time of $\mathrm{Ce}^{3+}$, viz. a few ten nanoseconds, which is highly favorable in highpower solid state lighting, for example laser lighting.
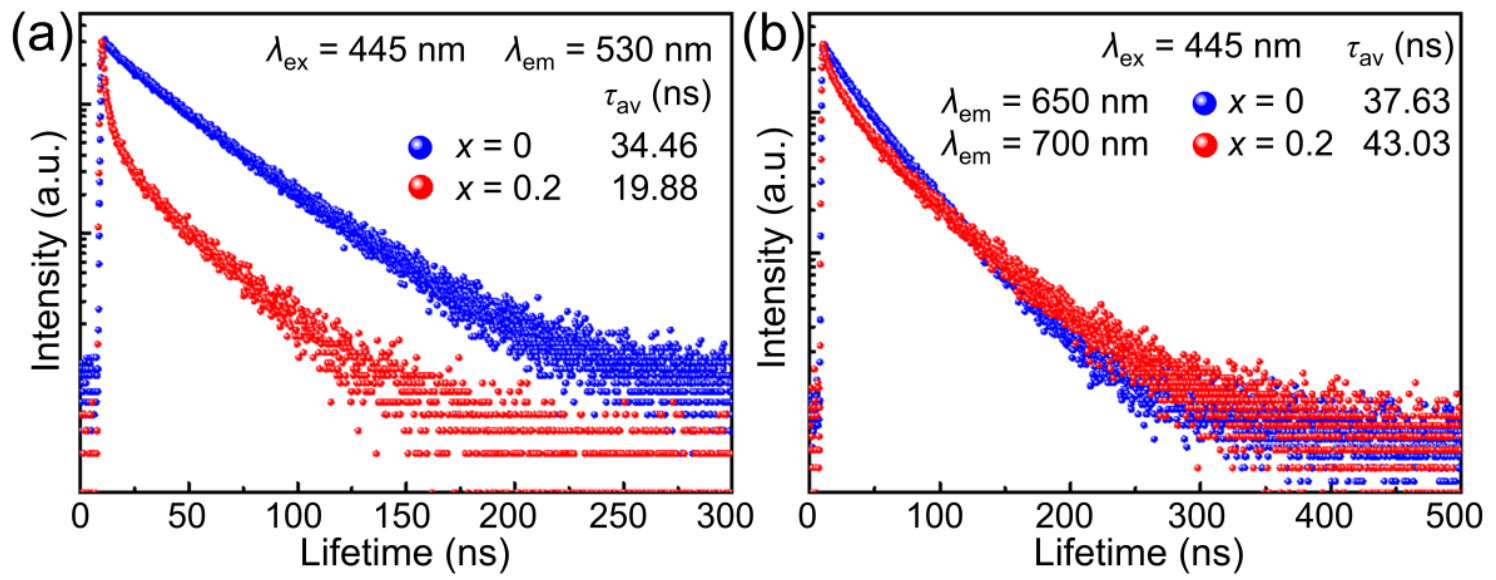

Figure S5. Decay curves of LSN:xAl ${ }^{3+}, \mathrm{Ce}^{3+}(x=0$ and 0.2) phosphors monitored at (a) 530, (b) 650 and $750 \mathrm{~nm}$ at room temperature using $445 \mathrm{~nm}$ blue LD as excitation source.

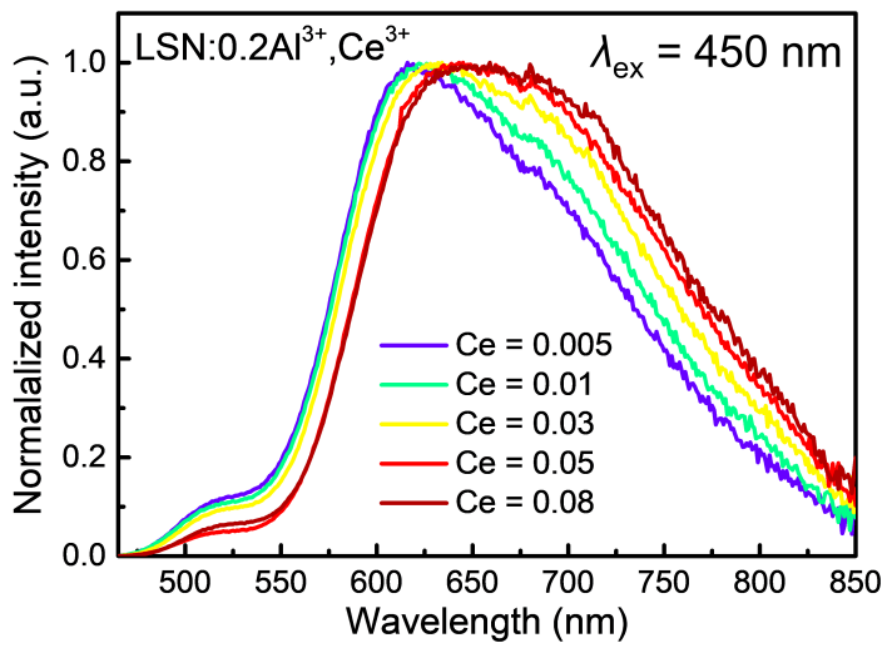

Figure S6. Emission spectra of $\mathrm{LSN}: 0.2 \mathrm{Al}^{3+}, \mathrm{Ce}^{3+}$ with different $\mathrm{Ce}^{3+}$ concentration (0.005 0.08) under $450 \mathrm{~nm}$ excitation 


\section{S5. First-principles calculation of $\mathrm{La}_{3} \mathrm{Si}_{5} \mathrm{AlON}_{10}: \mathrm{Ce}^{3+}$}

$\mathrm{Al} / \mathrm{Si}$ and $\mathrm{O} / \mathrm{N}$ possess very similar $\mathrm{X}$-ray diffraction character. Therefore, we cannot exclude safely the trace amount of oxygen in the synthesized powder just based on XRD results. The AI-O replacement by Si-N has been widely used in the luminescent tuning in the oxide-based phosphors. Here, we firstly study the possible charge compensating mechanism of $\mathrm{Al}^{3+}$ codoping: the substitution of $\mathrm{N}^{3-}$ by $\mathrm{O}^{2-}$.

For such goal, we use the $\mathrm{La}_{3} \mathrm{AISi}_{5} \mathrm{ON}_{10}$ (LASON) compound as paradigmatic structure, which has been synthesized from experiment, and its crystal structure is very similar to LSN (Figure S7). ${ }^{10,11}$ Experimental data indicated that the $\mathrm{Al}$ atoms occupy the Si1 sites and $\mathrm{O}$ atoms occupy the $\mathrm{N} 4$ sites. The Al occupancy preference have also been confirmed through our calculations, with around $0.4 \mathrm{eV}$ lower energy in the $\mathrm{Si} 1$ site than that of Si2 sites. Therefore, we assume that the usage of LASON as paradigmatic structure is reasonable.
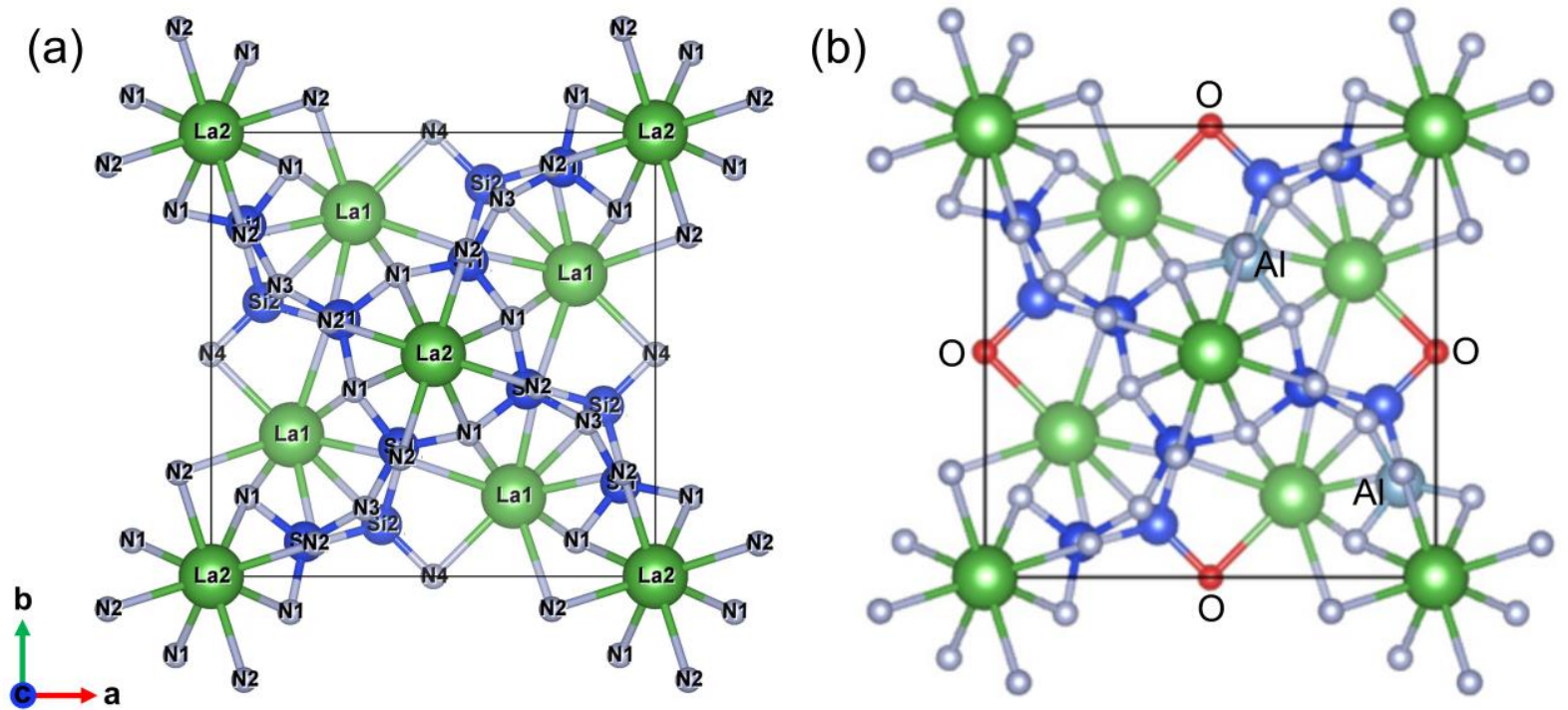

Figure S7. Crystal structures of (a) LSN and (b) LASON viewed along [001]

Figure S8 shows the band structure of LASON bulk, as well the LSN result for comparison. It can be clearly seen that both of two compounds have a very similar valence band, while the conduction band shape changes after the Al-O codoping in LASON. We check the charge density of VBM and CBM of LASON. The composition of VBM and CBM are mainly dominated $N 2 p$ and La $5 d$ state, respective. The LASON have an indirect band gap of $2.68 \mathrm{eV}$ (Kohn-Sham). This value is slightly smaller than that of LSN, which does not benefit for the $\mathrm{Ce}^{3+}$-doped phosphors since both of $\mathrm{Ce}-4 \mathrm{f}$ and $\mathrm{Ce}-5 \mathrm{~d}$ states need to locate inside the band gap for efficient white LED phosphors. 

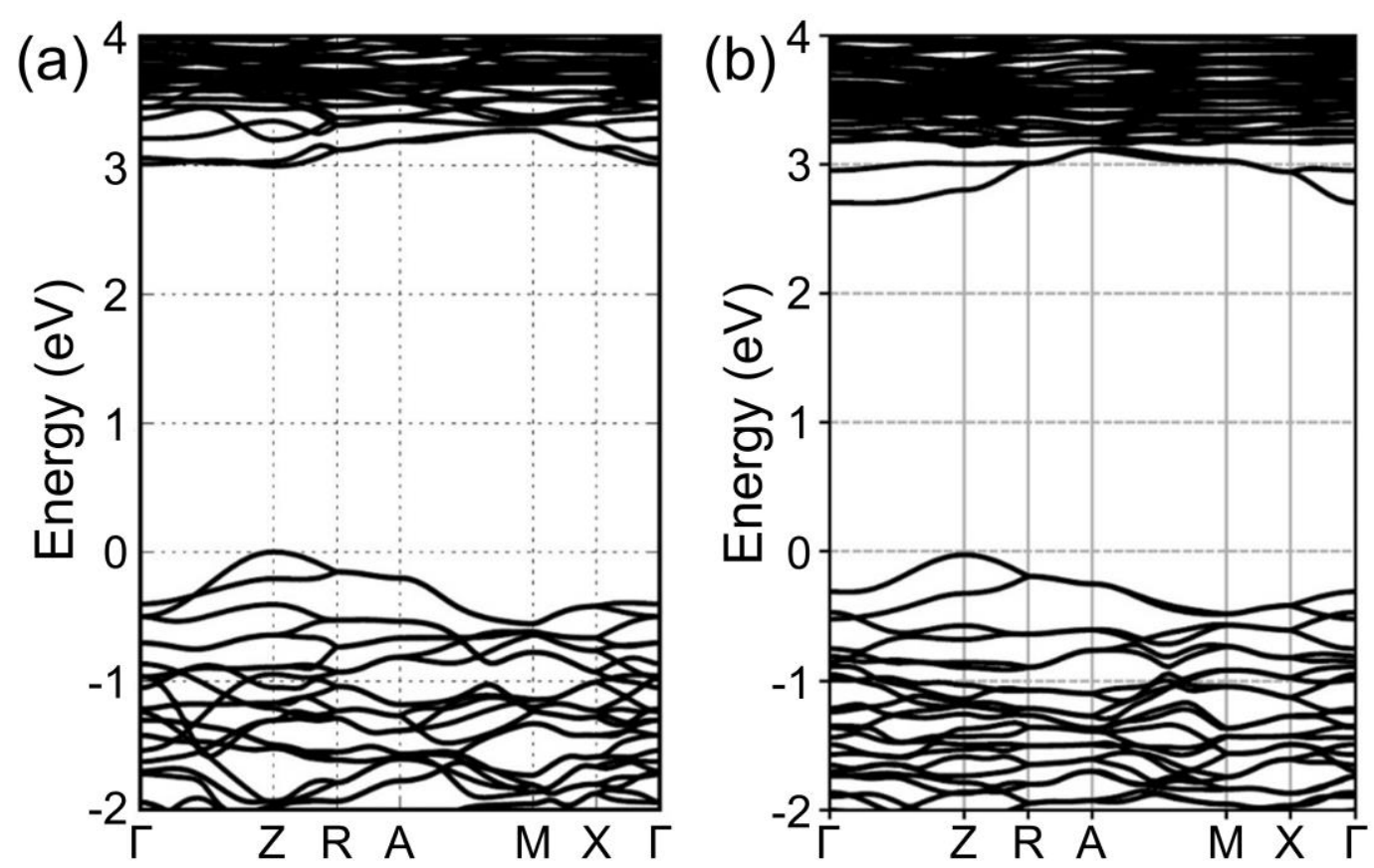

Figure S8. Electronic band structures of (a) LSN and (b) LASON bulks.

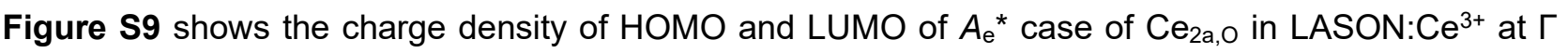
point. Table S3 lists the calculated transition energies of $\mathrm{Ce}_{2 \mathrm{a}, \mathrm{O}}$ and $\mathrm{Ce}_{4 \mathrm{c}, 0}$ in $\mathrm{LASON}: \mathrm{Ce}^{3+}$. The obtained results of LASON: $\mathrm{Ce}^{3+}$ indeed is similar with the previous ones of $\mathrm{LSN}: \mathrm{Ce}^{3+},{ }^{1}$ which is not consistent with the experimental data of additional red emission band, indicating the $\mathrm{Ce}_{\mathrm{Al}}$ is not derived from the substitution of $\mathrm{N}^{3-}$ by $\mathrm{O}^{2-}$. It should be noted that the experimental data for comparison is derived from the additional red emission band of $\mathrm{LSN}: 0.05 \mathrm{Al}^{3+}, \mathrm{Ce}^{3+}$ (low $\mathrm{Al}^{3+}$ concentration), because the $\mathrm{Al}^{3+}$ concentration in first-principles calculation is only $1 / 36$.

(a)

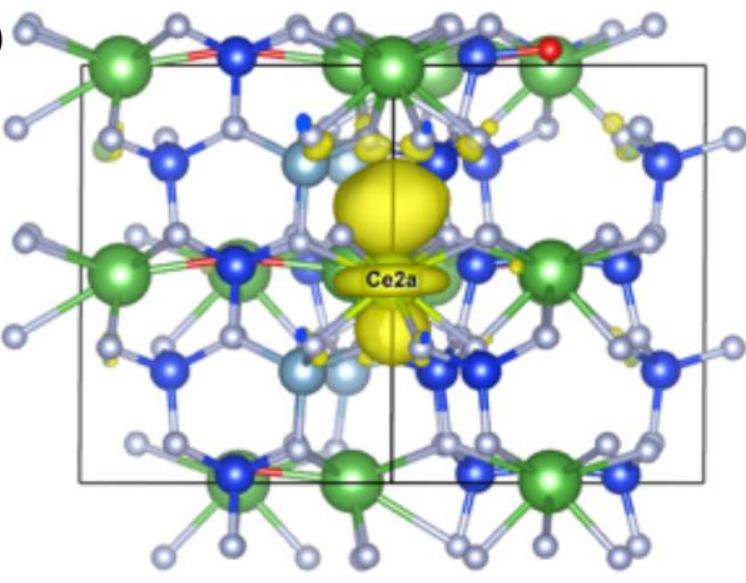

(b)

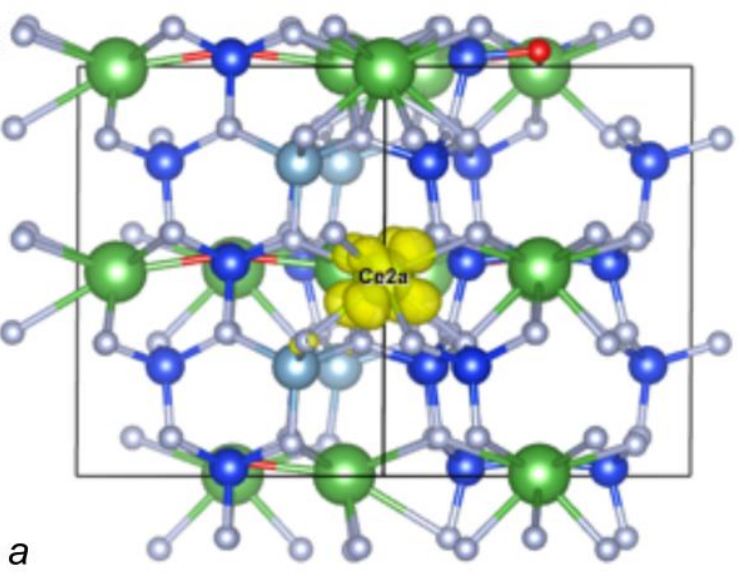

Figure S9. Charge density of (a) HOMO and (b) LUMO of $A_{e}{ }^{*}$ case of $\mathrm{Ce}_{2 \mathrm{a}, \mathrm{O}}$ in $\mathrm{LASON}: \mathrm{Ce}^{3+}$ at $\Gamma$ point. 
Table S3. The calculated transition energies of $\mathrm{Ce}_{2 a, 0}$ and $\mathrm{Ce}_{4 \mathrm{c}, \mathrm{O}}$ in $\mathrm{LASON}: \mathrm{Ce}^{3+}$ phosphor compared with the experimental data of $\mathrm{Ce}_{\mathrm{Al}}$.

\begin{tabular}{|c|c|c|}
\hline Case & $\mathrm{Ce}_{2 \mathrm{a}, \mathrm{O}}$ & $\mathrm{Ce}_{4 \mathrm{c}, \mathrm{O}}$ \\
\hline$A_{\mathrm{g}}$ & $-949.1047 \mathrm{Ha}$ & $-949.1035 \mathrm{Ha}$ \\
\hline$A_{g}{ }^{*}$ & $-948.9980 \mathrm{Ha}$ & $-948.9834 \mathrm{Ha}$ \\
\hline$A_{\mathrm{e}^{*}}$ & $-949.0046 \mathrm{Ha}$ & $-948.9931 \mathrm{Ha}$ \\
\hline$A_{\mathrm{e}}$ & $-949.0950 \mathrm{Ha}$ & $-949.0903 \mathrm{Ha}$ \\
\hline$\Delta E_{\mathrm{abs}}\left(E_{\mathrm{g}}{ }^{*}-E_{\mathrm{g}}\right)$ & $2.90 \mathrm{eV}$ & $3.27 \mathrm{eV}$ \\
\hline$\Delta E_{\mathrm{abs}}\left(\mathrm{Ce}_{\mathrm{Al}}, \mathrm{exp}.\right)$ & \multicolumn{2}{|c|}{$2.34 \mathrm{eV}$} \\
\hline$\Delta E_{\mathrm{em}}\left(E_{\mathrm{e}}{ }^{*}-E_{\mathrm{e}}\right)$ & $2.46 \mathrm{eV}$ & - \\
\hline$\Delta E_{\mathrm{em}}\left(\mathrm{Ce}_{\mathrm{Al}}, \mathrm{exp}.\right)$ & \multicolumn{2}{|c|}{$2.01 \mathrm{eV}$} \\
\hline
\end{tabular}




\section{S6. First-principles calculation of $\mathrm{LSN}: \mathrm{Al}^{3+}, \mathrm{Ce}^{3+}, \mathrm{VN}^{3+}$}

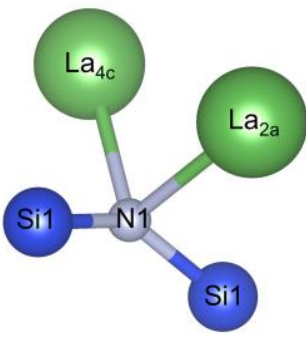

$\mathrm{N} 1-\mathrm{La}_{2 \mathrm{a}}: 2.650$

$\mathrm{N} 1-\mathrm{La}_{4 \mathrm{c}}: 2.551$

N1-Si1 : 1.724

N1-Si1 : 1.743

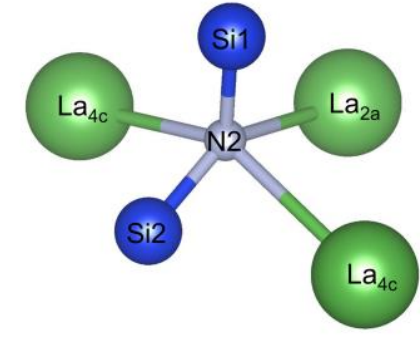

N2-La 2 : 2.644

$\mathrm{N} 2-\mathrm{La}_{4 \mathrm{c}}: 2.853$

$\mathrm{N} 2-\mathrm{La}_{4 \mathrm{c}}: 2.674$

$\mathrm{N} 2-\mathrm{Si} 1: 1.725$

N2-Si2 : 1.729

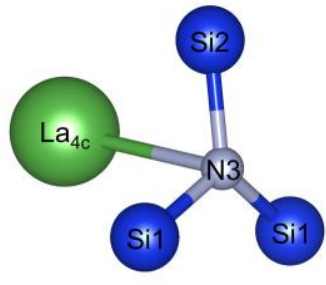

N3-La 4 : 2.863

N3-Si1 : 1.776

N3-Si2 : 1.764

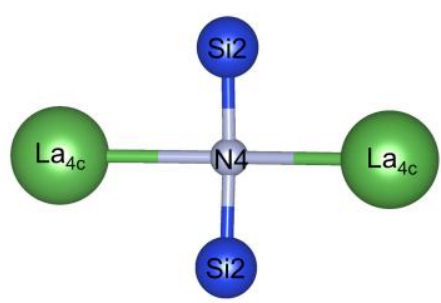

$\mathrm{N} 4-\mathrm{La}_{4 \mathrm{c}}: 2.623$

N4-Si2 : 1.686

Figure S10. The local environments and bonds length $(\AA)$ of four N sites in LSN crystal structure.

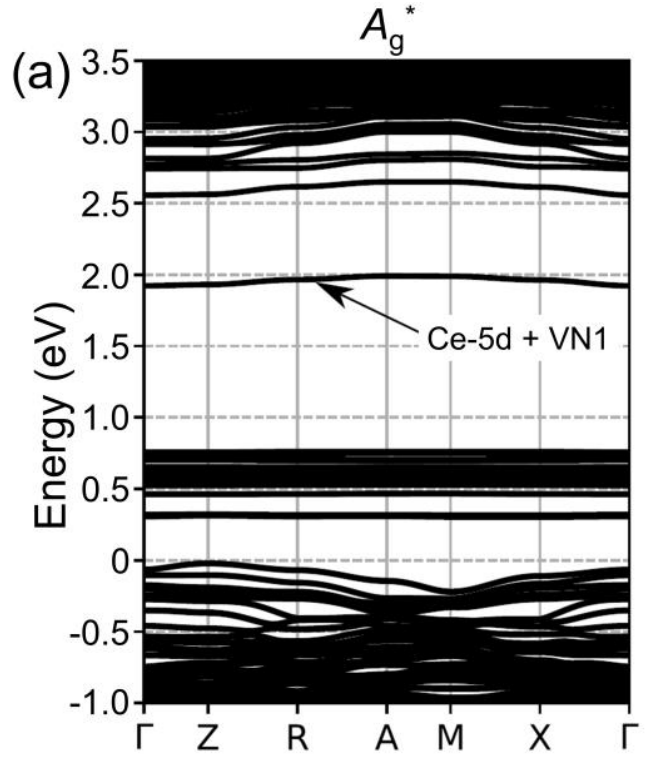

(b)

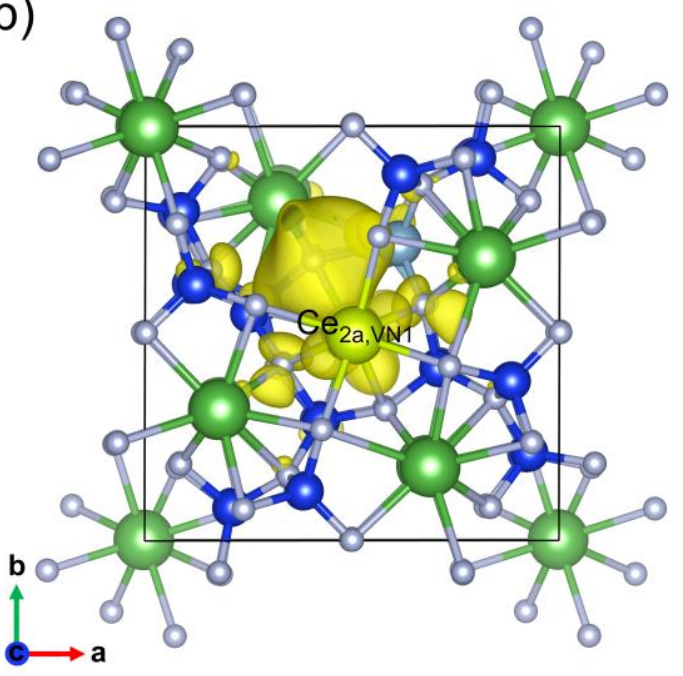

Figure S11. (a) Electronic band structures of excited state $\left(\mathrm{A}_{\mathrm{g}}{ }^{*}\right)$ of $\mathrm{Ce}_{2 \mathrm{a}, \mathrm{VN} 1}$ in $\mathrm{LSN}: \mathrm{Al}^{3+}, \mathrm{Ce}^{3+}, \mathrm{VN}^{3+}$; (b) charge density of $\mathrm{HOMO}$ of $\mathrm{Ag}^{*}$ case at $\Gamma$ point. 


\section{S7. First-principles calculation of $\mathrm{LSN}: \mathrm{Al}^{3+}, \mathrm{Ce}_{\mathrm{int}}{ }^{3+}$}

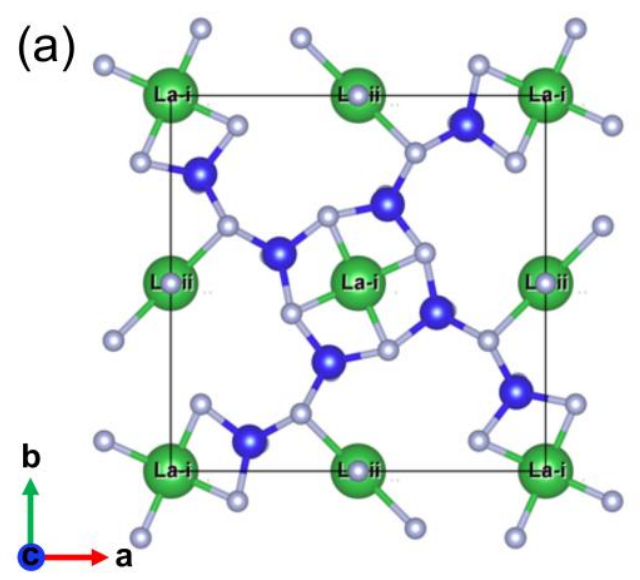

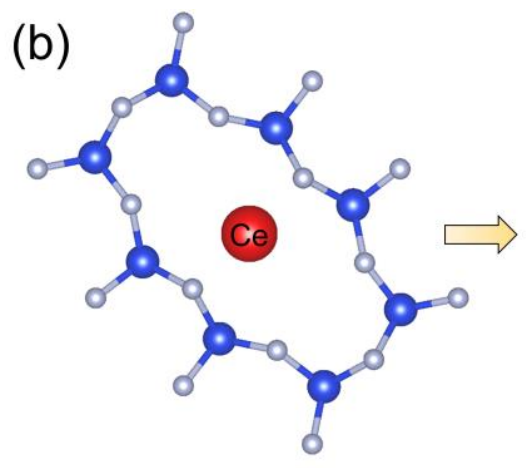

prefer void in $\left[\mathrm{Si}_{8} \mathrm{~N}_{8}\right]$ ring $\left[\mathrm{CeN}_{6}\right]$ polyhedron

Figure S12. (a) Two virtual interstitial $\mathrm{La}^{3+}$ sites along the $\left[\mathrm{Si}_{4} \mathrm{~N}_{4}\right]$ and $\left[\mathrm{Si}_{8} \mathrm{~N}_{8}\right]$ rings, Lai and Laii, respectively; (b) schematic viewing of $\mathrm{Ce}^{3+}$ ion in the void of $\left[\mathrm{Si}_{8} \mathrm{~N}_{8}\right]$ ring and the distorted 6 -fold coordinated octahedron of $\mathrm{Ce}_{\mathrm{ii}}$ by $\mathrm{N}$ atoms.

Table S5. The calculated transition energies of $\mathrm{Ce}_{i i}$ in $\mathrm{LSN}: \mathrm{Al}^{3+}, \mathrm{Ce}^{3+}$ phosphor, compared with the experimental data of additional red emission band $\left(\mathrm{Ce}_{\mathrm{Al}}\right)$.

\begin{tabular}{cc}
\hline Case & Ce $_{\mathrm{ii}}$ \\
\hline$A_{\mathrm{g}}$ & $-1420.9181 \mathrm{Ha}$ \\
$A_{\mathrm{g}}{ }^{*}$ & $-1420.8276 \mathrm{Ha}$ \\
$A_{\mathrm{e}}{ }^{*}$ & $-1420.8328 \mathrm{Ha}$ \\
$A_{\mathrm{e}}$ & $-1420.9131 \mathrm{Ha}$ \\
$\Delta E_{\mathrm{abs}}\left(E_{\mathrm{g}}{ }^{*}-E_{\mathrm{g}}\right)$ & $2.46 \mathrm{eV}$ \\
$\Delta E_{\mathrm{abs}}\left(E_{\mathrm{g}}{ }^{*}-E_{\mathrm{g}}\right)$, & $2.30 \mathrm{eV}$ \\
correction & $2.34 \mathrm{eV}$ \\
$\Delta E_{\mathrm{abs}}\left(\mathrm{Ce}_{\mathrm{Al}}, \mathrm{exp}.\right)$ & $2.19 \mathrm{eV}$ \\
$\Delta E_{\mathrm{em}}\left(E_{\mathrm{e}}{ }^{*}-E_{\mathrm{e}}\right)$ & $2.08 \mathrm{eV}$ \\
$\Delta E_{\mathrm{em}}\left(E_{\mathrm{e}}{ }^{*}-E_{\mathrm{e}}\right)$, & $2.01 \mathrm{eV}$ \\
correction & \\
$\Delta E_{\mathrm{em}}($ Ceel, exp. $)$ &
\end{tabular}

Table S6. The calculated thermodynamic transition energies of $\mathrm{Ce}_{2 a}$ and $\mathrm{Ce}_{i i}$ in $\mathrm{LSN}: \mathrm{Al}^{3+}, \mathrm{Ce}^{3+}$ phosphor.

\begin{tabular}{ccc}
\hline Case & $\mathrm{Ce}_{2 \mathrm{a}}$ & $\mathrm{Ce}_{\mathrm{ii}}$ \\
\hline$E_{\text {tot }}\left(\mathrm{Ce}^{3+, *}\right)$ & $-932.0129 \mathrm{Ha}$ & $-1420.8328 \mathrm{Ha}$ \\
$E_{\text {tot }}\left(\mathrm{Ce}^{4+}\right)$ & $-932.1360 \mathrm{Ha}$ & $1420.9816 \mathrm{Ha}$ \\
$\varepsilon\left(\mathrm{Ce}^{3+, *} / \mathrm{Ce}^{4+}\right)$ & $3.35 \mathrm{eV}$ & $4.05 \mathrm{eV}$ \\
\hline
\end{tabular}




\section{References}

(1) Jia, Y.; Miglio, A.; Poncé, S.; Gonze, X.; Mikami, M. First-principles Study of $\mathrm{Ce}^{3+}$-doped Lanthanum Silicate Nitride Phosphors: Neutral Excitation, Stokes Shift, and Luminescent Center Identification. Phy. Rev. B 2016, 93, 155111.

(2) Jia, Y.; Poncé, S.; Miglio, A.; Mikami, M.; Gonze, X. Assessment of First-Principles and Semiempirical Methodologies for Absorption and Emission Energies of $\mathrm{Ce}^{3+}$-Doped Luminescent Materials. Adv. Optical Mater. 2017, 5, 1600997.

(3) Jia, Y.; Miglio, A.; Mikami, M.; Gonze, X. Ab Initio Study of Luminescence in Ce-doped $\mathrm{Lu}_{2} \mathrm{SiO}_{5}$ : The Role of Oxygen Vacancies on Emission Color and Thermal Quenching Behavior. Phys. Rev. Mater. 2018, 2, 125202.

(4) Dorenbos, P. Thermal Quenching of $\mathrm{Eu}^{2+} 5 \mathrm{~d}-4 \mathrm{f}$ Luminescence in Inorganic Compounds. J. Phys.: Condens. Matter 2005, 17, 8103-8111.

(5) Freysoldt, C.; Grabowski, B.; Hickel, T.; Neugebauer, J.; Kresse, G.; Janotti, A.; Van de Walle, C. G. First-principles Calculations for Point Defects in Solids. Rev. Modern Phys. 2014, 86, 253-305.

(6) Freysoldt, C.; Neugebauer, J.; Van de Walle, C. G. Fully Ab Initio Finite-size Corrections for Chargeddefect Supercell Calculations. Phys. Rev. Lett. 2009, 102, 016402.

(7) Jia, Y.; Miglio, A.; Gonze, X.; Mikami, M. Ab-initio Study of Oxygen Vacancy Stability in Bulk and Cerium-doped Lutetium Oxyorthosilicate. J. Lumin. 2018, 204, 499-505.

(8) Yamane, H.; Nagura, T.; Miyazaki, T. La $\mathrm{Si}_{6} \mathrm{~N}_{11}$. Acta Cryst. 2014, E70, i23-i24.

(9) George, N. C.; Birkel, A.; Brgoch, J.; Hong, B. C.; Mikhailovsky, A. A.; Page, K.; Llobet, A.; Seshadri, R. Average and Local Structural Origins of the Optical Properties of the Nitride Phosphor $\mathrm{La}_{3-x} \mathrm{Ce}_{x} \mathrm{Si}_{6} \mathrm{~N}_{11}$ $(0<x \leq 3)$. Inorg. Chem. 2013, 52, 13730-13741.

(10) Lauterbach, R.; Schnick, W. $\mathrm{Nd}_{3} \mathrm{Si}_{5} \mathrm{AlON}_{10}$-Synthesis, Crystal Structure, and Properties of a Sialon Isotypic with $\mathrm{La}_{3} \mathrm{Si}_{6} \mathrm{~N}_{11}$. Z. Anorg. Allg. Chem. 2000, 626, 56-61.

(11) Ellens, A.; Fries, T.; Fiedler, T.; Huber, G. Illumination Unit Having at Least One LED as Light Source. US 6670748 B2, 2003. 